\title{
Las relaciones entre la autoridad civil y las órdenes religiosas en Filipinas durante el gobierno de don Pedro Manuel de Arandía
}

Marta María Manchado López

Universidad de Córdoba

Este trabajo ha sido realizado a partir de documentación inédita del Archivo General de Indias. Se centra en el estudio de los enfrentamientos que se produjeron entre el gobierno de Filipinas y las órdenes religiosas, durante el mandato de don Pedro Manuel de Arandía (1754-1759). Estos choques, que hunden sus raíces en las primeras medidas reformistas del gobernador, giraron en torno al Real Patronato y alcanzaron su máxima intensidad con la publicación de las Ordenanzas de Buen Gobierno de 1758, cuyo contenido y repercusiones son también analizados.

El gobierno de don Pedro Manuel de Arandía y Santisteban en Filipinas se extendió desde el 19 de julio de 1754, momento de su toma de posesión, hasta su muerte acaecida el 1 de junio de $1759 .{ }^{1}$ Se inscribe, pues, entre el problemático mandato de don Francisco José de Ovando y el gobierno interino de monseñor Miguel Lino de Ezpeleta, obispo electo de Cebú. ${ }^{2}$

Considerado por Montero y Vidal "uno de los más ilustres de las islas, por su celo en pro del buen servicio, por sus excelentes condiciones de mando y espíritu útilmente innovador”, Arandía mantuvo, sin embargo, unas relaciones extraordinariamente tensas con las órdenes religiosas, que culminaron en 1758 con la redacción de sus Ordenanzas de Buen Gobierno. $^{3}$

1 Era natural de Ceuta, aunque oriundo de Vizcaya. En el momento de ser designado para el gobierno de Filipinas era mariscal de campo, caballero de Calatrava, gentil-hombre de cámara del rey, capitán de las reales guardias españolas y mariscal de campo de los ejércitos reales. Se había distinguido en las guerras de Italia, y al recibir su nombramiento desempeñaba el gobierno de Almagro. Montero y Vidal, J.: Historia General de Filipinas, Madrid, 1894, T. I, págs. 527-548. Según este autor, la muerte sobrevino al gobernador la noche del 31 de mayo de 1759.

2 Molina, A.: Historia de Filipinas, Madrid, 1984, T. I, Cap. V. La interinidad del obispo Ezpeleta, "el primer filipino que recibe en sus manos el poder supremo de las islas", fue breve, siendo sustituido por el nuevo arzobispo de Manila, el recién llegado Antonio Manuel Rojo.

3 Montero y Vidal, J.: Historia de Filipinas, pág. 548. 
Este trabajo está dedicado al estudio de los enfrentamientos entre la máxima autoridad civil de las islas y las órdenes religiosas, a partir de la publicación de las citadas Ordenanzas, a las que consideraron atentatorias contra la dignidad de las religiones y sumamente perjudiciales para las islas. $^{4}$

\section{Los orígenes del conflicto}

Las desavenencias entre el nuevo gobernador y los regulares no parece que se iniciaran de modo inmediato tras la toma de posesión de Arandía, aunque algunas fuentes señalan la existencia de controversias surgidas entre éste y el arzobispo, don Pedro de la Santísima Trinidad, franciscano, por razones de etiqueta. ${ }^{5}$ Sin embargo, a decir de los religiosos, la animosidad del nuevo gobernador se manifestó desde los inicios de su gobierno. Así lo denuncia el definitorio de la Provincia del Santísimo Nombre de Jesús, en un extenso informe remitido al rey:

"Desde que llegó a estas islas vuestro gobernador mostró un ánimo muy opuesto al estado eclesiástico, y especialmente al regular. Sus conversaciones eran contra los religiosos, con tanto escándalo algunas veces que se le ha oído decir no creía en San Francisco, sólo porque había sido fraile. Varias veces se le ha oído que la gloria de haber desterrado a los religiosos de su palacio ninguno se la quitaría". ${ }^{6}$

Las relaciones entre Arandía y el clero regular se fueron envenenando a partir de la decisión del gobernador de hacer demoler conventos e iglesias construidas dentro del tiro de cañón de la plaza de Manila y que, por lo tanto, podían ser empleadas por los enemigos en caso de ataque a la ciudad. La resistencia de los religiosos frustró en gran medida la resolución del gobernador, y fue el punto de partida de las duras quejas que éste remitió a la Corte. ${ }^{7}$

4 La base del presente estudio es el extenso memorial remitido por el definitorio de la orden de San Agustín al rey con fecha de 4 de julio de 1758. También el informe sobre el estado de las islas Filipinas enviado al rey por el vicario provincial de los franciscanos, fray Antonio Tadeo Morales. Está fechado en Manila a 18 de julio de 1758. Ambos documentos se encuentran en el Archivo General de Indias, Filipinas, 1041.

5 Buzeta, M y Bravo, F.: Diccionario geográfico-estadístico-histórico de las islas Filipinas, Madrid, 1851, T. II, pág. 278

6 AGI, Filipinas, 1041. Memorial del definitorio de la Provincia del Santísimo Nombre de Jesús al rey, Tondo, 4 de julio de 1758.

7 Mas y Sanz, S.: Informe sobre el estado de las islas Filipinas en 1842, Madrid, 1966-1968, T. I, págs. 119-120. 
En realidad, esta decisión respondía a su programa de reformas en materia militar, orientado a conseguir un ejército más disciplinado, mejor remunerado y más eficaz ante las incursiones de los moros, que en estos años fueron muy frecuentes (especialmente intensas fueron las sufridas en las Visayas). La osadía de estos les había llevado a multiplicar sus ataques, e incluso a amenazar a la capital al asaltar el pueblo de Mariveles, muy próximo a Manila.

Esta política obedecía al contenido de las instrucciones reservadas que le habían sido entregadas antes de hacerse cargo de la gobernación de las islas. En ellas se insistía en que debía proteger a la población, hacer justicia y promover el progreso del país. Años más tarde, le serían remitidas dos órdenes reales fechadas el 1 de noviembre de 1758 y 26 de diciembre del mismo año, en que se le estimulaba a combatir a los piratas. Para ello y para defender la capital, debía hacer uso de la valiosa experiencia de los misioneros de las islas, "separándose de vanas empresas y nuevas conquistas", y poner empeño en acopiar el armamento necesario y construir las fortificaciones precisas. ${ }^{8}$

\section{Los enfrentamientos con los regulares y el Real Patronato}

El resquemor de Arandía hacia los regulares, fomentado por las persistentes denuncias que éstos hacían de los excesos de los alcaldes mayores sobre los indios, dio lugar a un episodio que escandalizó a las islas. Fue la huida de tres religiosos agustinos calzados de su convento, después de haber sido penitenciados por sus prelados debido a su mal comportamiento. Esto sucedía el 18 de julio de 1757. Refugiados en el convento de San Francisco, recurrieron al gobernador, quien desde el principio tomó su partido, y aún contra el parecer del fiscal, se negó a entregarlos a su provincial.

Avisados los huidos de las persistentes demandas de sus superiores, tuvieron tiempo suficiente para salir clandestinamente del convento franciscano y abandonar Manila, no sin antes presentarse al provisor del Arzobispado para que excomulgara al padre provincial y al guardián de

8 Véase Montero y Vidal, J.: Historia de Filipinas, pág. 544. Sobre la importancia que para la seguridad de la capital tenía la presencia de edificaciones en su campaña, véase los problemas a que tuvo que enfrentarse el gobernador Basco y Vargas, en Díaz-Trechuelo, M. L.: "La defensa de Filipinas en el último cuarto del siglo XVIII", Anuario de Estudios Americanos, T. XXI, Sevilla, 1964, páginas 145-209. 
San Francisco, así como al provincial de agustinos calzados, por haber intentado sacarlos de sagrado: "y después de varios pasos y paseos, cargados de armas y acompañados de gente armada" encontraron refugio en el pueblo de Calumpiz, administrado por el hermano de uno de ellos. ${ }^{9}$

Finalmente, el 3 de septiembre se logró que el gobernador transigiera con entregarlos a sus prelados en Manila, no sin antes recomendarles, por medio del oidor Francisco de Villacorta, que se les redujese la penitencia a que se habían hecho acreedores.

No paró aquí el asunto, ya que el gobernador los recibió en ocasiones en su palacio, aconsejándoles que clamaran por el patrocinio del Real Patronato. De esta forma, el 8 de octubre, cuando ya habían sido absueltos de la excomunión en que habían incurrido y parecía que las aguas habían vuelto a su cauce, el gobernador envió un ruego y encargo al provincial preguntándole, en virtud del Real Patronato, por las razones de haber privado del ministerio que servía a uno de los fugados, y por el traslado del párroco de Calumpiz.

En el primero de los casos, la razón habían sido los excesos y escándalos del religioso. En el caso de fray Alonso de Salazar, se le había ordenado salir de su pueblo en el mes de agosto, para evitar el que se volviera a refugiar allí su hermano; "pues decía vuestro gobernador que si no se les perdonaba todo, los volvería al lugar de donde los había sacado, por estar empeñada la palabra real". ${ }^{10}$

Que el conflicto no había quedado zanjado lo acredita el hecho de que se le impidió al provincial agustino enviar a la isla de Panay a dos religiosos, y con ellos a un hermano lego que había apoyado a los huidos. Incluso la petición formal del procurador general de la provincia fue desestimada, y se puso guardia con el fin de evitar la salida de religiosos agustinos de Manila.

El episodio escandaloso protagonizado por los agustinos huidos fue el pretexto de que se sirvió Arandía para plantear un problema extraordinariamente complejo, y así comprometer a los superiores regulares que habían tenido el valor de no someterse a su capricho. ${ }^{11}$

9 AGI, Filipinas, 1041. El definitorio de la Provincia del Santísimo Nombre de Jesús al rey, Tondo, 4 de julio de 1758 .

10 Ibídem. A los otros dos huidos no les afectaba la cláusula del Real Patronato, por ser uno corista (fray Alonso Ortiz), y por no tener ministerio el otro (fray José Salazar).

11 Manchado López, M. M. ${ }^{\text {a: }}$ Conflictos Iglesia-Estado en el Extremo Oriente Ibérico. Filipinas (1767-1787), Murcia, 1994. 
Hasta tres pliegos de ruego y encargo remitió el gobernador al provincial, cada uno más apremiante que el anterior, obteniendo siempre la misma respuesta, compartida por el definitorio de la orden en pleno: que la cláusula del Real Patronato a que aludía el gobernador no estaba en vigor en cuanto a los regulares de las islas, y que el rey lo sabía y lo aprobaba.

De nada sirvieron las órdenes conminatorias del gobernador, que llegó a amenazar al provincial con las temporalidades y la expulsión, y tampoco las razones que éste adujo para justificar la actitud de su orden.

El asunto pasó a vista del fiscal, quien convino en el extrañamiento del prelado, siempre que se estudiara previamente el tema en el Real Acuerdo. Reunido éste el 12 de diciembre de 1757, se determinó que no había causa para el destierro del provincial de agustinos, y que debía entenderse que el Real Patronato atañía a todas las órdenes de las islas, no a una sola.

La última maniobra del gobernador fue presentar el mismo día 12 a la Audiencia un escrito en nombre de los tres religiosos fugados que acudían al tribunal por vía de fuerza, y cuya redacción fue obra de don Santiago Orendaín, asesor y valido de Arandía. El documento, pese a no contar con la firma del abogado, fue admitido, pero se desestimó la petición. ${ }^{12}$

Pocos días después, el 18 de enero, se reprodujo el escándalo de la huida de los religiosos del convento de Manila, escalando las tapias con ayuda exterior. Según denuncia el definitorio, la participación o al menos la anuencia del gobernador en este rocambolesco episodio es clara, ya que la fuga se produjo aprovechando el ruido formado por la música que tocaban gentes del campo en las inmediaciones del convento, "para hacer las espaldas a los religiosos". No solamente había entre el gentío criados del gobernador, sino que el episodio se desarrolló a vista de los soldados de la puerta de Santa Lucía. Una vez fuera del convento, los dos religiosos que consiguieron su propósito fueron recibidos por Arandía, quien les obsequió con un refrigerio.

El 4 de marzo, consiguió huir por el mismo procedimiento el tercero de los religiosos, a quien se condujo a un convento de los recoletos extramuros de Manila, junto a sus compañeros. Allí permanecieron, sin que el

12 Don Santiago de Orendaín era el asesor y auténtico valido del gobernador Arandía. Había sido alcalde mayor, y se le había acusado de haber vendido por su cuenta los animales de labor de los indios. Molina señala que era persona de vida escandalosa y que la estrecha amistad que mantenía con el gobernador le granjeó a éste la animadversión popular. Molina, A.: Historia de Filipinas, cap. V. Por su parte, Martínez de Zúñiga atribuye las pésimas relaciones de Arandía con los religiosos a Orendaín, enemigo declarado de los eclesiásticos. Montero y Vidal, J.: Historia de Filipinas, pág. 546. 
provincial de recoletos se atreviera, por temor al gobernador, a entregarlos al superior de agustinos calzados, y eso a pesar de estar públicamente excomulgados.

Los excesos del gobernador y el escándalo público mortificaban al definitorio de la orden, pero más aún el hecho de no poderse defender, habida cuenta del terror que inspiraba el gobernador y que impedía remitir a la corte los testimonios que debían preparar sobre todo el asunto:

"Vuestro gobernador envía a V.M. varios testimonios contra lo que dice el provincial, pero también podrá este enviarlos a favor de lo que informa a V.M. en saliendo vuestro gobernador de aquí, porque ahora ninguno testificar por el mucho miedo que le tienen. Ni los escribanos reales se atreven a autorizar cosa alguna de estas por haberles mandado vuestro gobernador que no autoricen cosa alguna testimoniada por notario eclesiástico". ${ }^{13}$

Mientras tanto, el gobernador, que continuaba protegiendo a los fugados, reunía testimonios falsos sobre los regulares, y se aplicaba a la labor de animar a los elementos más díscolos de las órdenes a colocarse bajo su protección, tomando como excusa el Real Patronato.

\section{El estado de las islas durante el mandato de Arandía. Las Ordenanzas de Buen Gobierno de 1758}

El 18 de julio de 1758, fray Antonio Tadeo Morales, vicario provincial de la provincia de San Gregorio, remitía al rey un informe sobre la situación de las islas y de sus naturales. Por entonces las famosas Ordenanzas de Arandía se habían puesto en ejecución, y el resultado no podía ser más desalentador, a decir del franciscano, quien retrotrae la lamentable situación de las islas al momento mismo en que el gobernador inició su mandato.

"Paso a informar a V.M. el miserable estado de estas islas en lo espiritual y corporal, y la mutación tan lamentable que en estos cuatro años que lleva de gobierno de ellas este vuestro gobernador han tenido, que ni aun sombra de lo que eran parecen”. ${ }^{14}$

13 AGI, Filipinas, 1041. El definitorio de la provincia del Santísimo Nombre de Jesús al rey, Tondo, 4 de julio de 1758 .

14 Ibídem. Informe del vicario provincial de la provincia de San Gregorio, fray Antonio Tadeo Morales, al rey, convento de San Francisco de Manila, 18 de julio de 1758. 
La causa de los males que amenazaban arruinar totalmente las islas era el desprecio con que se trataba a las órdenes religiosas, la protección descarada a los alcaldes mayores por parte del gobernador, lo que les había hecho envalentonarse, y la consiguiente explotación y vejación de los naturales, hundidos cada vez más en la miseria y los vicios.

Por lo que respecta a los regulares, éstos se quejan amargamente de que el gobernador se esforzaba por aislarlos del clero secular, reprendiendo a aquellos clérigos que habían sido sorprendidos, por medio de espías, visitando a regulares en sus conventos, lo que no podían hacer sin mediar una razón que pareciera suficiente al gobernador.

Quizás se encuentre relacionado con esto la extraña actitud de Arandía ante los proyectos del obispo de Nueva Cáceres, a quien impidió realizar la visita pastoral de su diócesis. Efectivamente, no pudiendo realizar la inspección pastoral personalmente y careciendo de un clérigo secular competente, delegó en un recoleto, por ser esta la orden que tenía en la provincia de Albay, donde se concentraban la mayor parte de los seculares del obispado, algunos ministerios.

Llegado el obispo a Manila, expuso al gobernador su gran preocupación por la falta de clero secular en su diócesis, problema que intentaba paliar confiando la cura de almas a los recoletos, y por otras cuestiones que angustiaban su espíritu. A nada pareció prestar atención Arandía, quien sin embargo no olvidó decirle tomándole la mano y "como en confianza", que lo relativo a la visita del recoleto lo dejara porque no quería que "le alegaran ejemplar". ${ }^{15}$

Desconsolado y confundido al ver suspendida la visita proyectada, sin entender las vagas razones que aducía el gobernador, el obispo tuvo que regresar a su diócesis, no sin antes intentar una vez más la rectificación de Arandía, a través de una carta que le remitió a mitad de camino, por mano del recoleto a quien había confiado la visita:

"Y me recelo que acaso no se la habrá entregado, porque todos huyen lo que pueden de ir a tener conferencias con el dicho por la viveza y prontitud con que a todos los convence con sola la razón de su real y respetable autoridad". ${ }^{16}$

La publicación de las Ordenanzas de Buen Gobierno de 1758 dejó bien patente las pésimas relaciones entre las órdenes y el gobernador, y la

15 AGI, Filipinas, 1033. El obispo de Nueva Cáceres al rey, Nueva Segovia, 26 de junio de 1758.

16 Ibídem. 
voluntad de éste de humillarlas públicamente. No se trataba, como afirman los regulares, únicamente de la afrenta que el gobernador les infería. Su preocupación iba más lejos al comprobar cómo la situación de los naturales se degradaba, y con ello se destruía el trabajo que los religiosos tan pacientemente habían realizado.

Los puntos en que se centran las críticas de los regulares son las cláusulas relativas a los alcaldes mayores, a sus facultades y obligaciones (séptima, novena, decimonovena y vigésima), a los derechos de los indios (decimonovena y vigésima), y a los ministros doctrineros (décima y decimonovena).

En cuanto a los alcaldes mayores, era evidente la estrecha relación que mantenían con el gobernador, a quien procuraban agradar en todo. Deseosos de enriquecerse a costa de los indios, de su codicia nacía su aversión a los regulares, quienes tradicionalmente defendían a los naturales de la avaricia de aquéllos. ${ }^{17}$

Según denuncia el definitorio de la provincia del Santísimo Nombre de Jesús, el gobernador, consciente de que mientras los indios contemplaran con respeto y cariño a sus protectores, nada se podía hacer para satisfacer las apetencias de los alcaldes, ordenó la realización de pesquisas secretas sobre los religiosos. De ellas resultaron algunas faltas verdaderas, que los superiores podían haber reparado discretamente, y otras muchas inventadas, pero convenientemente apoyadas en testimonios falsos:

"pues a una insinuación de vuestro gobernador no faltan escribanos, ni testigos para todo, y es muy ordinario ahora, luego que vuestro gobernador oye alguna falta contra algún religioso, pedir luego testimonio, y para más explicar su odio, ha mandado sacar de los archivos cuantas faltas cometieron los religiosos desde la conquista". ${ }^{18}$

En virtud de las Ordenanzas, los alcaldes mayores monopolizaban el comercio en las provincias, lo que había provocado el aumento considera-

17 Las islas comprendían en esta época 17 alcaldías mayores, cuyos titulares actuaban como gobernadores y jueces de primera instancia en casos de cuantía inferior a 200 pesos, y como jueces de apelación en los casos juzgados por los gobernadorcillos con facultades de jueces en primer grado. Díaz-Trechuelo, M. L.: "Las Filipinas en su aislamiento, bajo el continuo acoso". En Historia General de España y América, T. IX-2, Madrid, 1984, págs. 129-153. Para el padre Castro, el alcalde mayor es "una bestia feroz". De Castro, A. M.: Misioneros agustinos en el Extremo Oriente (1565-1780), Madrid, 1954, pág. 271. En la pág. 394 afirma: "por la mayor parte son malos y peores que ladrones, dice el Sr. Solórzano en su Política Indiana, tomo segundo".

18 AGI, Filipinas, 1041. El definitorio de la provincia del Santísimo Nombre de Jesús al rey, Tondo, 4 de julio de 1758 
ble de los precios e incluso escasez en la propia capital. A esto se sumaba la imposición de una nueva alcabala, que había reducido el número de champanes que, procedentes de las provincias, se dirigían a la capital cargados de abastos. También pesaban las injusticias que padecían los indios por parte de quienes estaban encargados de su cobro, y el cansancio ante el abuso que suponía que se les confiscaran sus champanes cuando el gobierno lo necesitaba, y el que se los devolvieran dañados o destrozados. ${ }^{19}$

Ante esta situación, la provincia del Santísimo Nombre de Jesús denunció al alcalde mayor de la Provincia de la Pampanga, que había estancado la carne, el pan y las candelas, y prohibía la salida de dichos géneros para acapararlos todos. Los religiosos intentaron convencerle de los perjuicios que ocasionaba su actitud, pero éste comunicó las quejas de los agustinos al gobernador, quien le recomendó que las desoyera. Tres años después, Arandía no había tomado providencia alguna para poner fin a los abusos del alcalde mayor.

En opinión del definitorio, la denuncia de los agustinos fastidió tanto al gobernador que no cejó en su empeño de buscar el modo de atacarles, encontrándolo en el episodio escandaloso de los tres fugados del convento, referido anteriormente.

Los alcaldes mayores se habían hecho cargo también de las escuelas (decimoséptima y vigésima cláusulas), lo que era entendido por los religiosos como un paso firme hacia su destrucción, puesto que poco empeño habrían de poner en forzar a sus paisanos a enviar a los niños a estudiar, si los padres preferían mandarlos a trabajar a las sementeras. Por supuesto, también se ponía fin a los trabajos que realizaban los niños en los conventos cuando era necesaria alguna reparación, para lo que se les eximía ocasionalmente, según las Ordenanzas, de la obligación de acudir a la escuela.

Hasta entonces los religiosos siempre habían cuidado de la asistencia de los niños a las clases y supervisado la tarea del maestro. Ahora se temía que la indolencia de los padres y la natural renuencia de los niños acabaran con las escuelas que tanto trabajo había costado poner en funcionamiento.

Otro problema venía a añadirse a este: el empeño del gobernador de llevar a su estricto cumplimiento las disposiciones reales sobre la enseñanza del castellano en las islas. De esta forma, había ordenado que los niños

19 Champán: "embarcación sínica del tamaño de un patache español, pero inferior al junco de los mismos chinos". W. E. Retana, edición del Estadismo de las islas Filipinas, de J. Martínez de Zúñiga, T.II, Madrid, 1893, pág. 513. 
lo aprendieran en la escuela y, para garantizar que así se hiciera, había prohibido la impresión de libros en las lenguas del archipiélago.

Pero los maestros, fuera de los de Manila, tampoco conocían en su inmensa mayoría el castellano, y se les amenazaba desde las Ordenanzas con castigos, si no enseñaban en esta lengua. Con todo esto era fácil deducir que no se encontraría quien quisiera desempeñar ese cargo, y de haberlo, su trabajo sería totalmente estéril. El castellano no se difundiría, entre otras razones, por el corto número de españoles que habitaban las islas, y que estaban concentrados en su mayoría en Manila. La reflexión de los religiosos resulta en este punto extraordinariamente clarividente:

"Dado que se halle maestro, están los niños cuatro o cinco años en la escuela, donde oyen cuatro palabras en castellano; salen de allí y no hablan sino en su lengua. Al cabo de los cuatro años sabrán el rezo en castellano como papagayos, sin entender lo que rezan, y no lo sabrán en lengua que es lo que entenderían, y así de ningún modo lo sabrán". ${ }^{20}$

La novena cláusula de las Ordenanzas encomienda a los alcaldes mayores el velar para que no les falten a los indios animales para el trabajo de sus tierras; sin embargo, se había extendido la práctica de quitarles los que tenían para emplearlos en el arrastre de las maderas, lo que hacía que las tierras quedaran incultas.

A esto se sumaban los inconvenientes derivados de las novedades introducidas en los cortes de madera que anualmente realizaban los indios para el rey. Con anterioridad a las disposiciones de Arandía, los cortes cesaban los meses precisos para atender al trabajo de sus campos y, además, si algún indio no podía acudir cuando le tocaba, enviaba a otro en su lugar. Ahora, los cortes se prolongaban llegando incluso a durar hasta quince meses; por otra parte, el indio que no acudía cuando le correspondía, por no poder o por el temor de ser maltratado, debía pagar cinco pesos que se emplearían en el salario del sustituto. Esto suponía que los indios trabajaban y también pagaban y, puesto que no era fácil encontrar quien sustituyera a los que no iban, todo el dinero desaparecía sin que se supiera su destino, aunque se suponía que era el bolsillo del cabo encargado de la supervisión, o el de otra persona.

20 Véase nota 18. Sobre el problema del castellano en Filipinas, véase el trabajo de Merino,

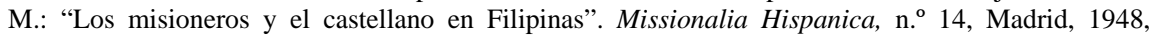
págs. 271-323. También Manchado López, M. M. a. "Notas para el estudio de la difusión del castellano en Filipinas. La situación de la provincia de la Pampanga en la segunda mitad del siglo XVIII". En Homenaje a Lourdes Díaz-Trechuelo, Córdoba, 1991, págs. 61-75. 
Estos, además, tenían de hecho el monopolio del establecimiento de tiendas en las cercanías de los cortes, en las que vendían los productos al precio que querían. De esta forma, sin estar sujetos a ningún control, se enriquecían al tiempo que los indios dejaban allí sus sueldos y, empobrecidos y mal nutridos, llegaban incluso a morir "en el monte o en el pueblo, si el Padre no los socorre cuando enfermos llegan". ${ }^{21}$

Era también práctica asentada durante anteriores gobiernos que algunos religiosos acudieran como capellanes a los cortes. Así controlaban el trato que recibían los indios y el comportamiento de los cabos, denunciando sus excesos en caso de producirse. Sin embargo, Arandía, probablemente movido por el poco aprecio que sentía hacia los regulares, había resuelto que los capellanes de los cortes fueran clérigos. Estos, por su temperamento más pusilánime, no daban parte de cosa alguna.

Por otro lado, tradicionalmente se venía pagando a los indios en los cortes mensualmente, pero ahora los pagos se demoraban meses, como había sucedido en la Laguna de Bay, donde habían transcurrido hasta seis meses sin que se les pagaran los correspondientes salarios.

A todo esto se sumaba otra novedad en perjuicio de los indios: hasta entonces se les había permitido cortar libremente madera de los montes de sus pueblos para construir sus casas y para otros menesteres. Desde el gobierno de Arandía eso les estaba prohibido sin obtener antes la necesaria licencia, para lo que tenían que desplazarse a Manila.

Consecuencia de esta nueva disposición era que, para ahorrarse los gastos de los desplazamientos, de la licencia, y las molestias, no tenían más remedio que vivir en condiciones deplorables:

"se están viviendo muchos en una casilla. Por ser muy pequeñas, y ellos de poca vergüenza, ser muy contra la cristiana y racional modestia, y no podrán los ministros de doctrina obligarles a que cada familia tenga casa aparte, como hasta ahora les han obligado, porque como son unos pobres dirán y dicen que no tienen para tantos gastos.”22

A todo esto se sumaban otras prácticas introducidas durante el gobierno de Arandía que empeoraban la situación de los indios. Así, por ejemplo, si antes los naturales de la provincia de Tondo eran encargados de conducir

21 Véase nota 18. Díaz-Trechuelo, M. L.: "Filipinas". En Historia General de España y América, T. XI-1, Madrid, 1983, pág. 530.

22 AGI, Filipinas, 1041. El vicario provincial de la provincia de San Gregorio, fray Antonio Tadeo Morales, al rey, Manila, 18 de julio de 1758. 
las balsas que debían transportar las maderas de los cortes, por ser estos menores allí, ahora también los de las provincias de Bulacán y la Pampanga debían hacerlo igualmente, a pesar de cargar con la mayor parte de los cortes. Habiendo reclamado un religioso que les pagasen por ello un salario, no se le hizo caso, alegando que los indios estaban obligados a ese servicio.

También era muy frecuente pedir indios para el servicio del rey en diferentes menesteres y, una vez presentados los convocados, conmutarles el trabajo que debían hacer por un pago en metálico que esquilmaba a los indios y sobre cuyo paradero nada se había averiguado. Esto había sucedido en la provincia de Tondo cuando el gobernador determinó que debían cortarse los nipales y algunos otros árboles. Quince indios de los cuarenta convocados en uno de los pueblos llegaron con un pequeño retraso, cuando se acababa de leer la lista, pero no fueron admitidos, forzándoseles a entregar tres pesos a cambio. Lo mismo se repitió en otras localidades de la provincia.

Todo esto hacía que, como aseguraba el vicario provincial de San Gregorio, "nunca se han visto los indios más gravados y molestados que en estos tiempos", lo que había empujado a algunos de ellos a apostatar y a unirse a las partidas de moros que amenazaban la seguridad de las islas..$^{23}$

Un problema especialmente grave por sus nefastas consecuencias era la libertad de juego. Establecido bajo la excusa de socorrer la renta real, los religiosos denuncian que era un porcentaje muy bajo el que se destinaba a ello. El resto se repartía entre los beneficiados del gobernador.

Arandía había publicado por bando que sólo se autorizaban los juegos lícitos, y que los ministros de doctrina velarían por que así fuera. Sin embargo, cuando llegaron las primeras denuncias del prior de Tambobón, de la provincia de Tondo, no se le tomó en consideración, antes bien, se le procuró hacer la vida imposible, retirándole el servicio del convento.

En realidad siempre había habido juegos de gallos en los días festivos, y otros que se realizaban clandestinamente. Ahora, con el bando del gobernador, habían proliferado en todas las provincias, dedicándose los indios (incluso mujeres y niños) a los dados, naipes, gallos... de día y de noche, "por lo que estos naturales, de suyo inclinados a los juegos, están tan embebidos en ellos que ni se acuerdan de Dios, ni de sus almas". ${ }^{24}$ Por supues-

23 Ibídem.

24 Ibídem.

Anuario de Estudios Americanos 
to, tampoco de su sustento, ya que había auténticas bandas de coimes que recorrían los pueblos esquilmando a los naturales que, hundidos en el vicio y la pobreza, incluso iban desnudos.

En cuanto a los ministros de doctrina, la decimonovena cláusula de las Ordenanzas les privaba de buena parte de los jóvenes que actuaban como sacristanes y ayudaban en todo lo referente al culto divino. ${ }^{25}$ Esta disposición se justificaba, según el gobernador, en la insistencia real para que los indios fueran bien tratados y no sufrieran vejaciones.

Sin embargo, los religiosos entendían que no era sólo una ayuda en su trabajo, sino un medio que les permitía conocer a los indios, ya que el servicio como sacristanes se hacía por turnos, al tiempo que favorecía el que éstos se acostumbraran a la vida en comunidad y a acudir a la escuela, lo que se encargaba de controlar el religioso. Además, al carecer las iglesias de rentas para pagar esos servicios, los ministros se encontraban con enormes dificultades para realizar con decencia y eficacia su labor, "de suerte que causa irrisión a los mismos indios ver el culto divino cómo est ahora, respecto de lo que estaba antes": 26

"No hay quien quiera servir a la Iglesia, ni acompañar al Santísimo cuando lo llevan los ministros de doctrina por Viático a los enfermos; y como a estos naturales les entra la fe por los ojos, viendo este poco culto en las iglesias y el Santísimo Viático sin más luz que un farol, van perdiendo o resfriándose en la fe con gravísima destrucción de estas cristiandades". ${ }^{27}$

La citada cláusula establecía además que todos los criados de los doctrineros estaban obligados a realizar los mismos polos y servicios que los demás indios. Esto era una discriminación que ofendía profundamente a los religiosos, ya que todos los criados de españoles estaban exentos de dichos servicios en virtud de concesión real. El enojo que esto les producía les lleva a decir que se había llegado al extremo de que en esas tierras ser religioso y ministro de doctrina era "degenerar de españoles".

A esto se añadía el problema del salario que debían pagar los religiosos a sus criados. Las Ordenanzas establecían que éste debía ajustarse a la tasa establecida para cada provincia. Esto obligaba a los religiosos a

25 A comienzos de siglo se discutió este punto, en tiempos del gobernador don Domingo de Zabalburu, y con consulta del Real Acuerdo se estableció en ocho el número de sacristanes en los pueblos que excedían de quinientos tributarios.

26 AGI, Filipinas, 1041. El definitorio de la provincia del Santísimo Nombre de Jesús al rey, Tondo, 4 de julio de 1758 .

27 Véase nota 22. 
pagar a sus sirvientes dos pesos y la comida, por trabajos que a su juicio no eran pesados, sabiendo que en Manila, "donde corre más la plata", los españoles sólo pagaban a sus criados mensualmente con la comida y un peso.

La undécima cláusula prohibía cobrar terrazgo por el solar que ocuparan las casas, bajo ningún concepto, amenazando con castigos a quien lo hiciera. El problema radicaba en la gran facilidad con que se construían las casas los indios. Estos, además, solían levantarlas en medio de las sementeras que labraban, con lo que, amparados en las Ordenanzas, se negaban a pagar ni por el solar de la vivienda, ni por las tierras de labor.

Esto perjudicaba a las órdenes religiosas que poseían algunas tierras (como en la provincia de Tondo), y máxime cuando se sabía que los terrazgos eran cobrados por otras personas, bajo la especie de que eran para el gobernador, por haberles dado las tierras, o para el justicia mayor.

El gobernador justificaba sus disposiciones asegurando que eran el medio para que los indios rompieran los lazos de dependencia de los religiosos, y obedecieran a las autoridades civiles. Esta afirmación contenía en realidad una acusación grave contra las órdenes, ya que presuponía que pretendían suplantar la legítima jurisdicción de las autoridades civiles, aprovechándose de su predicamento sobre los naturales.

En este sentido, en la cláusula décima se decía que quienes tuvieran oficios representativos de la jurisdicción real serían informados de que, si eran llamados por el religioso doctrinero para tratar algún asunto, debían exigir previamente por escrito que les fuera expuesto el motivo de la entrevista. Esta disposición ataba las manos de los religiosos que hasta ahora habían sido los abogados y defensores de los indios ante los abusos que sufrían por parte de las autoridades locales. En realidad, desde la publicación de las Ordenanzas, los indios no acudían en demanda de consejo a los padres, y estos se sentían impotentes ante la creciente autoridad que el gobierno concedía a los alcaldes mayores.

Pero no era sólo el asunto de las Ordenanzas lo que había creado profundo malestar entre las religiones de las islas. Otras disposiciones habían mostrado bien a las claras la animadversión del gobernador. Así, por ejemplo, el religioso que se embarcaba para las Visayas tenía que solicitar una licencia cuya expedición le costaba dos pesos. Y lo peor de todo era que ésta, como otras disposiciones tomadas por Arandía, no figuraba por escrito, "todo va a lo verbal", con el fin de guardarse las espaldas y evitar que en el futuro se le pudieran echar en cara excesos sancionados con su firma. 
De momento nadie se atrevía a replicarle en nada, temiendo que su intento le saliera, como sucedía, muy caro.

Este había sido el caso del prior de Tondo que, tras manifestar su desacuerdo con el comportamiento del gobernador en el asunto de los religiosos fugados, vio como aquel privó a su convento de una renta que disfrutaba en virtud de dos concesiones del gobierno y dos sentencias concomitantes de la Real Audiencia. Además la privación de dichas rentas se ejecutó sin oír al convento y sin ni siquiera citarle por si tenía algo que alegar.

Por otra parte, los religiosos describen al gobernador como una persona tornadiza, pronta a realizar promesas que fácilmente olvidaba, e incluso negaba haber hecho. Sus actos iban en la misma dirección. Así sucedió, por ejemplo, en el caso de los sangleyes, a los que ordenó taxativamente que se concentraran en Manila, por el mal ejemplo que daban a los naturales en los pueblos. ${ }^{28}$

Muchos de ellos acudieron al gobierno pidiendo una licencia para permanecer en las provincias, la cual consiguieron, previo pago de doce pesos. Lo mismo sucedió con la prohibición publicada en el mes de febrero de que no se hicieran más cortes de madera, sin previa licencia del gobierno, alegando que convenía así al real servicio. El procurador general de franciscanos la solicitó para la reconstrucción de conventos e iglesias que habían sido arrasados por un temblor de tierra, pero le fue denegada la licencia que, a cambio de plata, se le concedió a un sangley.

Este afán de acopiar plata mediante la multiplicación de derechos, trámites y licencias, no tenía a juicio de los religiosos más objeto que el enriquecimiento personal de los beneficiados del gobernador y de su amplia clientela, formada sobre todo, por los alcaldes mayores.

El vicario provincial de franciscanos denuncia, en este sentido, el descuido del gobierno en lo relativo a la defensa de las islas y la protección de sus habitantes:

"lo que no puede omitir el informante es ver la ninguna providencia que vuestro gobernador da para que se fabriquen galeras y otras embarcaciones para defender a las provincias de estas islas de los repetidos insultos con que cada día las acometen los moros de este archipiélago, lo que con el seguro de que no hay en vuestro puerto de Cavite embarcaciones que salgan a castigar su osadía no cesan de asolar provin-

28 Sobre la política mantenida en las islas con relación a los sangleyes, véase DíazTrechuelo, M. L.: "Las Filipinas en su aislamiento bajo el continuo acoso", págs. 132-133. 
cias y profanar iglesias, saquear los vasos y ropas sagradas y cautivar a innumerable gente de todos estados que inconsolable mente lloran la pesada servidumbre en que se hallan". ${ }^{29}$

\section{Las consecuencias de la política de Arandía}

Para los religiosos estaba claro que lo que se pretendía con las Ordenanzas era acabar con el respeto y cariño que los naturales sentían por los religiosos. En este punto, el definitorio de la provincia del Santísimo Nombre de Jesús se muestra optimista: no se podía destruir la obra de siglos en unos pocos años. Sin embargo, el vicario provincial de San Gregorio denuncia la soledad y el abandono en que habían quedado algunos franciscanos, que carecían de servicio que les hiciera la comida y que incluso habían sufrido el robo por parte de los indios de la madera que tenían para el uso del convento.

Las consecuencias de las Ordenanzas eran, en opinión de los regulares, desastrosas. Pero podían ser aún peores de no ponérsele remedio:

\footnotetext{
"los indios serán indómitos, no los sujetarán los alcaldes, ni el real tributo podrán cobrar, ni se podrá conservar esta cristiandad. ¿Qué había de hacer un alcalde mayor en una provincia con veinte o treinta mil indios que están a su cargo, si los Padres ministros no le hicieran lado?.”30
}

Sin embargo, no eran sólo las Ordenanzas lo que criticaban los regulares; por encima de ellas sus quejas se dirigen contra el gobierno de Arandía en su conjunto, al considerarlo inspirado en la animadversión que sentía hacia ellos. Consecuencia de este "mal gobierno" era el desquiciamiento del orden de cosas hasta entonces imperante en el archipiélago. Las relaciones entre la autoridad civil y los regulares se habían ido tensando a medida que el gobernador desautorizaba a los prelados y despojaba a las órdenes de parte de sus tierras. La obediencia debida por los religiosos a sus prelados se había resentido y, lo que era más grave, los doctrineros estaban perdiendo su ascendiente sobre los indios, cuyas condiciones de vida se habían degradado ostensiblemente.

29 AGI, Filipinas, 1041. El vicario provincial de la provincia de San Gregorio, fray Antonio Tadeo Morales, al rey, Manila, 18 de julio de 1758.

30 Véase nota 26. 